NASA/TM-2019-220028

\title{
Reformulation of Oxide Growth Equations for Oxidation of Silicon Bond Coat in Environmental Barrier Coating Systems
}

Roy M. Sullivan

Glenn Research Center, Cleveland, Ohio 


\section{NASA STI Program . . . in Profile}

Since its founding, NASA has been dedicated to the advancement of aeronautics and space science. The NASA Scientific and Technical Information (STI) Program plays a key part in helping NASA maintain this important role.

The NASA STI Program operates under the auspices of the Agency Chief Information Officer. It collects, organizes, provides for archiving, and disseminates NASA's STI. The NASA STI Program provides access to the NASA Technical Report Server-Registered (NTRS Reg) and NASA Technical Report ServerPublic (NTRS) thus providing one of the largest collections of aeronautical and space science STI in the world. Results are published in both non-NASA channels and by NASA in the NASA STI Report Series, which includes the following report types:

- TECHNICAL PUBLICATION. Reports of completed research or a major significant phase of research that present the results of NASA programs and include extensive data or theoretical analysis. Includes compilations of significant scientific and technical data and information deemed to be of continuing reference value. NASA counter-part of peer-reviewed formal professional papers, but has less stringent limitations on manuscript length and extent of graphic presentations.

- TECHNICAL MEMORANDUM. Scientific and technical findings that are preliminary or of specialized interest, e.g., "quick-release" reports, working papers, and bibliographies that contain minimal annotation. Does not contain extensive analysis.
- CONTRACTOR REPORT. Scientific and technical findings by NASA-sponsored contractors and grantees.

- CONFERENCE PUBLICATION. Collected papers from scientific and technical conferences, symposia, seminars, or other meetings sponsored or co-sponsored by NASA.

- SPECIAL PUBLICATION. Scientific, technical, or historical information from NASA programs, projects, and missions, often concerned with subjects having substantial public interest.

- TECHNICAL TRANSLATION. Englishlanguage translations of foreign scientific and technical material pertinent to NASA's mission.

For more information about the NASA STI program, see the following:

- Access the NASA STI program home page at http://www.sti.nasa.gov

- E-mail your question to help@sti.nasa.gov

- Fax your question to the NASA STI Information Desk at 757-864-6500

- Telephone the NASA STI Information Desk at 757-864-9658

- Write to:

NASA STI Program

Mail Stop 148

NASA Langley Research Center Hampton, VA 23681-2199 
NASA/TM-2019-220028

\section{Reformulation of Oxide Growth Equations for Oxidation of Silicon Bond Coat in Environmental Barrier Coating Systems}

Roy M. Sullivan

Glenn Research Center, Cleveland, Ohio

National Aeronautics and

Space Administration

Glenn Research Center

Cleveland, Ohio 44135 


\section{Acknowledgments}

This study was funded by the Advanced Air Transport Technology project and the Transformational Tools and Technologies project under NASA's Aeronautics Research Mission Directorate. The author is grateful to Drs. Nathan Jacobson, Kang Lee, Bryan Harder, and Ben Kowalski for helpful discussions regarding environmental barrier coating technologies.

This report is a formal draft or working paper, intended to solicit comments and ideas from a technical peer group.

This report contains preliminary findings, subject to revision as analysis proceeds.

This work was sponsored by the Advanced Air Vehicle Program at the NASA Glenn Research Center

This work was sponsored by the Transformative Aeronautics Concepts Program.

Level of Review: This material has been technically reviewed by technical management.

Available from

NASA STI Program

Mail Stop 148

NASA Langley Research Center

Hampton, VA 23681-2199
National Technical Information Service 5285 Port Royal Road Springfield, VA 22161

703-605-6000

This report is available in electronic form at http://www.sti.nasa.gov/ and http://ntrs.nasa.gov/ 


\title{
Reformulation of Oxide Growth Equations for Oxidation of Silicon Bond Coat in Environmental Barrier Coating Systems
}

\author{
Roy M. Sullivan \\ National Aeronautics and Space Administration \\ Glenn Research Center \\ Cleveland, Ohio 44135
}

\section{Summary}

The formulation of Deal and Grove for the oxidation of silicon and the growth of a silica layer is revisited to include the effects of a protective coating layer. The linear-parabolic equation of the form $x_{o}^{2}+A x_{o}=B t$ is still applicable, but the expression for the constant $A$ must be modified to account for the coating. The modified expression for $A$ is a linear function of the coating thickness. The modified formulation is applied to assess recently published experimental results for the oxidation of a silicon bond coat in an environmental barrier coating. Application of the modified expression for $A$ to the experimental results leads to an estimate of the ratio of the oxidant permeability in the oxide to its permeability in the coating.

\subsection{Introduction}

Ceramic matrix composites (CMCs) possess many desirable properties that make them attractive candidate materials for many high-temperature applications in the aerospace and energy industries. Unfortunately, they possess one characteristic that may limit their utilization in these applications. The constituents within many types of CMCs will oxidize at high temperatures in environments containing oxidants such as water or oxygen. The development of durable coating technologies to protect the CMCs from oxidation is essential to the utilization of CMCs in the various high-temperature applications.

One such coating system consists of a silicon bond coat applied to the bare substrate followed by one or more rare-earth silicate (e.g., $\mathrm{Yb}_{2} \mathrm{Si}_{2} \mathrm{O}_{7}$ ) coating layers. Although the coating system is designed to protect the underlying substrate, the coating system itself is susceptible to oxidation. Oxidants will diffuse through the coating layers and oxidize the silicon bond coat. Over time, a silica layer will form between the silicon bond coat and the adjacent layer. The formation of the silica layer causes stresses in the silica layer and the other coating layers and can lead to failure of the coating system. The stresses are generated by the difference in the molar volumes of silicon and silica. Stresses will also be generated through the combined effect of thermal excursions from the stress-free temperature and the thermal expansion differences between the silica layer and the various coating layers. Stress magnitudes are a function of the silica thickness. In order to assess the durability of a coating system, it is necessary to be able to predict the silica thermally grown oxide (TGO) thickness as a function of time.

The physics of the oxidation of an uncoated surface of silicon exposed to an oxidative environment and the formation of a layer of silica has been described by Deal and Grove (1965). They derived and demonstrated the application of the equation $x_{o}^{2}+A x_{o}=B t$ to simulate the growth of the silica TGO layer. In this equation, $x_{o}$ is the oxide scale thickness, $t$ is the time, and $A$ and $B$ are constants. Possessing both linear and second-order terms in $x_{o}$, this equation is commonly referred to as the "linear-parabolic growth equation." Deal and Grove derived expressions for the constants and showed that $A$ is a function of the reaction rate constant and the diffusivity of the oxidant within the oxide and $B$ is a function of the 
diffusivity and solubility of the oxidant within the oxide. As such, the constants $A$ and $B$ are each a function of temperature and are dependent upon the oxidant. Through experimental measurements, Deal and Grove obtained the values of $A$ and $B$ as a function of temperature in both dry and wet oxygen environments within the range 700 to $1200{ }^{\circ} \mathrm{C}$.

This report examines the oxidation of a silicon bond coat under one or more coating layers. Herein, the formulation from Deal and Grove is revisited to include the effect of the coating. It will be shown that the linear-parabolic growth rate equation from Deal and Grove is still relevant. However, the expression for the constant $A$ must be modified to account for the coating layers. The reformulation is performed in Sections 2.0, 3.0, and 4.0, and the modified expression for $A$ is obtained. In Section 5.0, recently published experimental results from Lee (2018) for the oxidation of a silicon bond coat in an environmental barrier coating (EBC) are reviewed. By fitting the experimental results from Lee to the linear-parabolic equation $x_{o}^{2}+A x_{o}=B t$, the numerical values for the constants $A$ and $B$ are obtained. Application of the modified expression for $A$ leads to an estimate of the ratio of the oxidant permeability in the oxide to its permeability in the coating.

\subsection{Problem Description}

The problem to be examined is illustrated in Figure 1. The coating system consists of only two layers: a silicon bond coat and a protective coating layer. The oxidants exist in the surrounding gas environment as the molecules $\mathrm{O}_{2}$ or $\mathrm{H}_{2} \mathrm{O}$. The oxidants diffuse through the coating and oxidize the silicon bond coat forming a layer of silica. For the continual growth of the oxide thickness, diffusion must occur across both the coating and the oxide layer. The oxide layer has thickness $x_{o}$, which increases with time. The thickness of the coating is constant and is denoted as $\delta$.

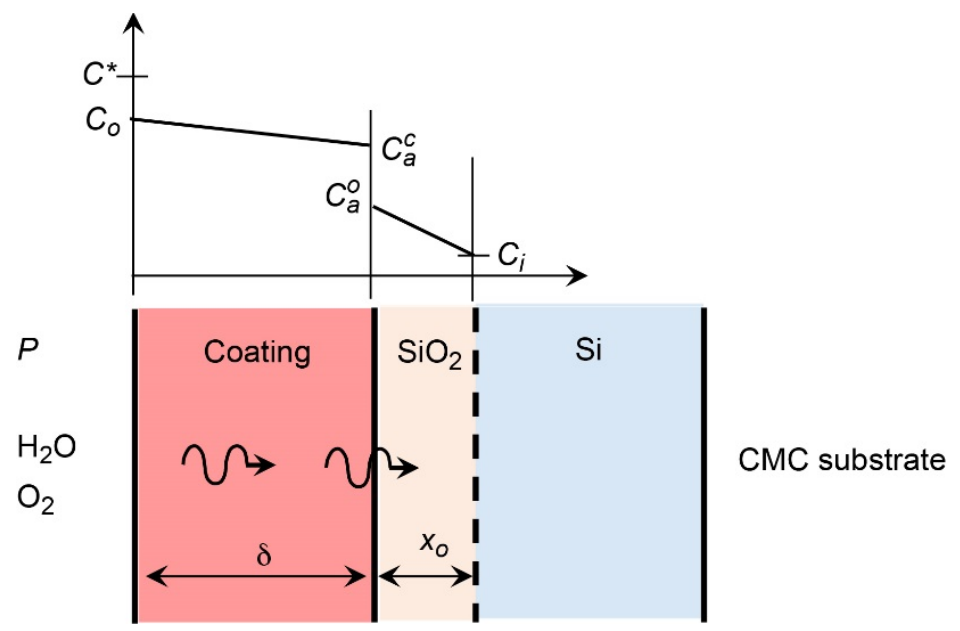

Figure 1.-Two-layer environmental barrier system for ceramic matrix composites (CMCs) consisting of silicon bond coat and single topcoat, with silica formation between them. Layer thicknesses are not necessarily to scale. $P$ is oxidant partial pressure in gas environment, $C^{*}$ is equilibrium oxidant concentration at outer surface of coating, $C_{0}$ is oxidant concentration at outer surface of coating, $C_{a}^{c}$ is oxidant concentration in coating at coating/oxide interface, $C_{a}^{o}$ is oxidant concentration in oxide at coating/oxide interface, $C_{i}$ is oxidant concentration at oxide/silicon interface, $\delta$ is coating thickness, and $x_{0}$ is oxide scale thickness. 
In the study of the oxidation of an uncoated silicon surface, the nature of the oxidants as they migrate across the silica layer was a key consideration. Several authors (Deal and Grove, 1965; Doremus, 1976; Lamkin, Riley, and Fordham, 1992; Norton, 1961; and Williams, 1965) concluded that the diffusing specie is molecular $\mathrm{O}_{2}$ and $\mathrm{H}_{2} \mathrm{O}$ for oxidation in dry and wet oxygen, respectively. This assertion is supported by (1) measurements of diffusivity versus temperature, which show that the enthalpy of diffusion is too low to include the dissociation of the oxidants (Doremus, 1976) and (2) a linear relation between the rate of diffusion and the oxidant pressure (Doremus, 1976; Norton, 1961; and Williams, 1965). Indeed, Deal and Grove's formulation was predicated on the assumption that the oxidizing diffusant was molecular $\mathrm{O}_{2}$ or $\mathrm{H}_{2} \mathrm{O}$. Thus far, there has been less discussion in the literature regarding the migration of the oxidants in the rare-earth silicate coatings used in EBC systems. Recently, Richards et al. (2016) and Wada et al. (2017) have speculated that the transport of the oxidants through $\mathrm{Yb}_{2} \mathrm{Si}_{2} \mathrm{O}_{7}$ is by diffusion of ions along the grain boundaries.

In this study, the following two possible oxidant transport mechanisms will be examined: (1) oxygen and water diffuse across the oxide and coating layers in the form of molecular $\mathrm{O}_{2}$ and $\mathrm{H}_{2} \mathrm{O}$ in dry and wet oxygen, respectively, and (2) the $\mathrm{O}_{2}$ and $\mathrm{H}_{2} \mathrm{O}$ dissociate, and the products diffuse across the coating and oxide layers in the form of either monatomic $\mathrm{O}$ or the ion $\mathrm{O}^{2-}$ when in dry oxygen and $\mathrm{OH}^{-}$when in wet oxygen. Any effect of the charge to enhance or retard the ion diffusion will be neglected. Diffusion is assumed to be driven by concentration gradients only. In both of the aforementioned cases, the oxidant in the coating and in the oxide will be treated as condensed mixtures, where the oxidant represents the solute. The solute concentration is assumed to be low enough so that Henry's law and Sieverts's law are applicable. In addition, it is assumed that the system is under steady-state conditions, following the formulation of Deal and Grove (1965).

Under steady-state conditions, the oxidant concentration is linear within the coating and oxide layers (see Figure 1). The concentration at the exterior surface of the coating is $C_{o}$. The equilibrium concentration $C^{*}$ is the concentration of the oxidant at the outer surface that is in equilibrium with the partial pressure of the oxidant in the gas environment. It would be the oxidant concentration in the coating if there were no diffusion and no oxidation reaction. The oxidant concentration is discontinuous at the coating/oxide interface. At the interface, the concentration in the coating is $C_{a}^{c}$, and in the oxide it is $C_{a}^{o}$. The concentration at the oxide/silicon interface is $C_{i}$.

\subsection{Modified Linear-Parabolic Reaction Constants}

The reformulation of the linear-parabolic equation to account for a coating will first be performed assuming the oxidants diffuse across the coating and oxide layers as the molecules $\mathrm{O}_{2}$ and $\mathrm{H}_{2} \mathrm{O}$, in accordance with Deal and Grove (1965). In this case, the equilibrium concentration $C^{*}$ may be expressed as a function of the partial pressure of the oxidant in the gas environment $P$ using Henry's law: $C^{*}=H_{c} P$, where $H_{c}$ is the Henry's law solubility coefficient for the oxidant in the coating. At the coating/oxide interface, the oxidant in the coating and in the oxide are assumed to be in chemical equilibrium. The oxidant in the coating and in the oxide at the interface are assumed to also be in equilibrium with the oxidant in a theoretical gas reservoir at an oxidant partial pressure $P^{a}$. As a result, one may write $C_{a}^{c}=H_{c} P^{a}$ and $C_{a}^{o}=H_{o x} P^{a}$, where $H_{o x}$ is the Henry's law solubility coefficient for the oxidant in the oxide. One may also write $C_{a}^{c}=\bar{H} C_{a}^{o}$, where $\bar{H}=H_{c} / H_{o x}$. The concentration distributions have been drawn in Figure 1 such that $C_{a}^{c}>C_{a}^{o}$; however, this is not necessarily the case. The magnitudes of $C_{a}^{c}$ and $C_{a}^{o}$ depend upon the values of $H_{c}$ and $H_{o x}$, respectively. 
Following the formulation of Deal and Grove (1965), the steady-state fluxes are

$$
\begin{gathered}
F_{1}=h\left(C^{*}-C_{o}\right) \\
F_{2}=D_{c} \frac{\left(C_{o}-C_{a}^{c}\right)}{\delta}=D_{c} \frac{\left(C_{o}-\bar{H} C_{a}^{o}\right)}{\delta} \\
F_{3}=D_{o x} \frac{\left(C_{a}^{o}-C_{i}\right)}{x_{o}} \\
F_{4}=k C_{i}
\end{gathered}
$$

All fluxes are understood to be the number of oxidant molecules crossing through a unit area per unit time. The first expression in Equation (1) defines the flux of oxidant molecules from the gaseous environment onto the exterior surface. The coefficient $h$ relates the flux of oxidant from the gas to the surface under the driving force $C^{*}-C_{o}$. It is akin to the convection coefficient in Newton's law of cooling (Deal and Grove, 1965). The second and third expressions utilize Fick's law to define the oxidant flux through the coating and oxide layers, respectively. They assume that the concentration of the oxidant is linear within the layers. The diffusivity of either $\mathrm{O}_{2}$ or $\mathrm{H}_{2} \mathrm{O}$ through the oxide layer is denoted as $D_{o x}$; the diffusivity of the coating is $D_{c}$. The fourth expression is the flux at the point of the chemical reaction, at the interface between the oxide and silicon. It defines the number of oxidant molecules that are consumed in the chemical reaction per unit area per unit time. The symbol $k$ is the reaction rate constant. A firstorder reaction rate is assumed.

Under steady-state conditions, $F_{1}=F_{2}=F_{3}=F_{4}$. Upon equating the expressions in Equation (1), one may obtain

$$
\begin{aligned}
& \frac{C_{i}}{C^{*}}=\frac{1}{\frac{k}{h}+\bar{H}\left(1+\frac{k x_{o}}{D_{o x}}\right)+\frac{k \delta}{D_{c}}} \\
& \frac{C_{a}^{o}}{C^{*}}=\frac{1+\frac{k x_{o}}{D_{o x}}}{\frac{k}{h}+\bar{H}\left(1+\frac{k x_{o}}{D_{o x}}\right)+\frac{k \delta}{D_{c}}} \\
& \frac{C_{o}}{C^{*}}=\frac{\bar{H}\left(1+\frac{k x_{o}}{D_{o x}}\right)+\frac{k \delta}{D_{c}}}{\frac{k}{h}+\bar{H}\left(1+\frac{k x_{o}}{D_{o x}}\right)+\frac{k \delta}{D_{c}}}
\end{aligned}
$$

Substituting the expressions from Equation (2) into those of Equation (1) yields the oxidant flux $F$ :

$$
F=F_{1}=F_{2}=F_{3}=F_{4}=\frac{k C^{*}}{\frac{k}{h}+\bar{H}\left(1+\frac{k x_{o}}{D_{o x}}\right)+\frac{k \delta}{D_{c}}}
$$


The oxidant flux and rate of increase in the TGO thickness are related by

$$
\frac{\mathrm{d} x_{o}}{\mathrm{~d} t}=\frac{F}{N_{1}}
$$

where $N_{1}$ is the number of oxidant molecules incorporated in a unit volume of oxide. Substituting Equation (3) into Equation (4) and rearranging leads to

$$
\left(\bar{H}+\frac{k}{h}+\frac{k \delta}{D_{c}}\right) \mathrm{d} x_{o}+\bar{H} \frac{k}{D_{o x}} x_{o} \mathrm{~d} x_{o}=\frac{k C^{*}}{N_{1}} \mathrm{~d} t
$$

Integrating Equation (5) and rearranging leads to an expression of the form

$$
x_{o}^{2}+A x_{o}=B t+x_{o i}^{2}+A x_{o i}
$$

where

$$
\begin{gathered}
A=2 D_{o x}\left(\frac{1}{k}+\frac{1}{\bar{H} h}+\frac{\delta}{\bar{H} D_{c}}\right) \\
B=\frac{2 D_{o x}}{\bar{H} N_{1}} C^{*}
\end{gathered}
$$

and $x_{o i}$ is the oxide thickness at $t=0$.

The expression for $A$ given by Deal and Grove (1965) for the case without a coating is

$$
A=2 D_{o x}\left(\frac{1}{k}+\frac{1}{h}\right)
$$

Deal and Grove estimated the values for $k$ and $h$ and determined that $h \gg k$. Thus, Equation (7a) may be approximated as

$$
A \sim \frac{2 D_{o x}}{k}
$$

Provided the value of $\bar{H}$ is not a small number, the same argument can be used to simplify Equation (6b). Thus, for a layer of coating, $A$ may be approximated as

$$
A \sim 2 D_{o x}\left(\frac{1}{k}+\frac{\delta}{\bar{H} D_{c}}\right)
$$

The only difference between the expression for $A$ in Equations (7b) and (8) is the addition of the second term in Equation (8). To distinguish between the case with and without a coating, let us assign

$$
A^{\prime}=A+\frac{2 D_{o x}}{\bar{H} D_{c}} \delta
$$


where the prime indicates the presence of a coating layer. The relationship between diffusivity and permeability is discussed in the Appendix. Using Equation (24) from the Appendix, Equation (9) may be written as

$$
A^{\prime}=A+\frac{2 \gamma_{o x}}{\gamma_{c}} \delta
$$

where $\gamma_{o x}$ and $\gamma_{c}$ are the permeability of the oxidant molecules in the oxide and coating layers,

respectively. Thus, $A^{\prime}$ is a linear function of the coating thickness; a plot of $A^{\prime}$ versus the coating thickness is a straight line that possesses a slope of $2 \gamma_{o x} / \gamma_{c}$ and intersects the vertical axis at $A$.

Note that if there are multiple coating layers applied over the bond coat, then Equation (10) becomes

$$
A^{\prime}=A+2 \sum_{i=1}^{N} \frac{\gamma_{o x}}{\gamma_{c i}} \delta_{i}
$$

where $N$ is the number of coating layers and $\gamma_{c i}$ and $\delta_{i}$ represent the permeability and thickness of the layers, respectively.

Substituting Henry's law $C^{*}=H_{c} P$ into Equation (6c) yields

$$
B=\frac{2 D_{o x}}{N_{1}} H_{o x} P
$$

which is the expression for $B$ given by Deal and Grove for the case without a coating layer. Thus, the parameter $B$ is independent of whether or not there is a coating. Only the parameter $A$ is affected by the presence of a coating.

Equation (6a) may now be rewritten as

$$
x_{o}^{2}+A^{\prime} x_{o}=B t+x_{o i}^{2}+A^{\prime} x_{o i}
$$

where $A^{\prime}$ and $B$ are obtained from Equations (11) and (12), respectively. As in the formulation of Deal and Grove, Equation (13) can be written more concisely as

$$
x_{o}^{2}+A^{\prime} x_{o}=B(t+\tau)
$$

where

$$
\tau=\frac{x_{o i}^{2}+A^{\prime} x_{o i}}{B}
$$

The equation for $x_{o}$ as a function of time is then obtained by applying the quadratic formula to Equation (14a) to yield

$$
x_{o}=\frac{A^{\prime}}{2}\left\{\left[1+\frac{4 B}{A^{\prime 2}}(t+\tau)\right]^{1 / 2}-1\right\}
$$




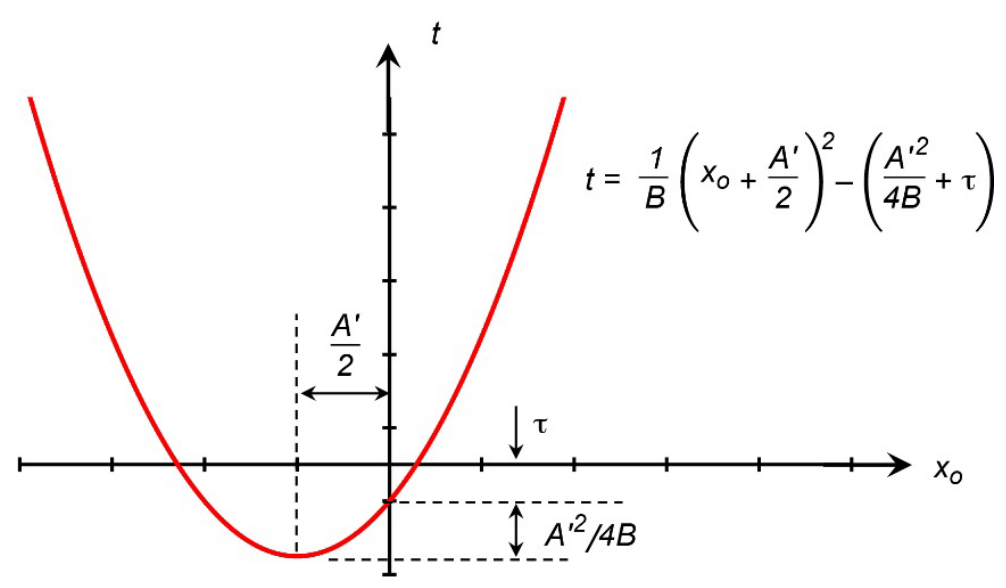

Figure 2.- Sketch of parabola in $\left(x_{0}, t\right)$ coordinate system with focal length $\mathrm{B} / 4$ and vertex at $\left(-A^{\prime} / 2,-\left(A^{\prime 2} / 4 B+\tau\right)\right)$.

The effect of the coating on the oxide growth may be understood more thoroughly using graphical methods. To this end, Equation (14a) may be rewritten in the form

$$
t=\frac{1}{B}\left(x_{o}+\frac{A^{\prime}}{2}\right)^{2}-\left(\frac{A^{\prime 2}}{4 B}+\tau\right)
$$

Equation (16) is recognized as the equation for a parabola in the $\left(x_{o}, t\right)$ coordinate system with a focal length $B / 4$ and a vertex located in the third quadrant at the point $\left(-A^{\prime} / 2,-\left(A^{\prime 2} / 4 B+\tau\right)\right)$, as illustrated in Figure 2. The shape of the parabola is defined by the value of $B$, and its position in the $\left(x_{o}, t\right)$ coordinate system is defined by the values of both $A^{\prime}$ and $B$. Thus, the effect of adding a coating, or additional coatings, is to shift the parabola to the left a distance $\Delta A^{\prime} / 2$ and downward vertically a distance $\left(\Delta A^{\prime}\right)^{2} / 4 B$, but it will not affect the shape of the parabola because it does not affect the value of $B$.

\subsection{Dissociation of $\mathrm{O}_{2}$ and $\mathrm{H}_{2} \mathrm{O}$ and Diffusion of Products}

Let us now consider the possibility that the oxidants $\mathrm{O}_{2}$ and $\mathrm{H}_{2} \mathrm{O}$ dissociate and the dissociation products, either monatomic $\mathrm{O}$ or the ions $\mathrm{O}^{2-}$ or $\mathrm{OH}^{-}$, diffuse across the coating and oxide layers. In this case, the concentrations $C^{*}, C_{o}, C_{a}^{c}, C_{a}^{o}$, and $C_{i}$ denote the concentrations of the dissociation products at the respective locations. Furthermore, the concentrations $C^{*}, C_{a}^{c}$, and $C_{a}^{o}$ are given by Sieverts's law as

$$
\begin{gathered}
C^{*}=\sqrt{S_{c} P} \\
C_{a}^{c}=\sqrt{S_{c} P^{a}} \\
C_{a}^{o}=\sqrt{S_{o x} P^{a}}
\end{gathered}
$$

where $S_{o x}$ and $S_{c}$ are Sieverts's law constants for the oxide and coating, respectively.

The same series of algebraic manipulations that produced Equations (1) through (9) may be performed, except now the expressions in Equations (17a), (17b), and (17c) are used for the 
concentrations. The derivations lead to an equation identical to Equation (6a), but now the constants $A^{\prime}$ and $B$ become

$$
A^{\prime}=A+2\left(\frac{D_{o x}}{D_{c}}\right)\left(\frac{\sqrt{S_{o x}}}{\sqrt{S_{c}}}\right) \delta
$$

and

$$
B=2 D_{o x}\left(\frac{\sqrt{S_{o x}}}{\sqrt{S_{c}}}\right)\left(\frac{C^{*}}{N_{1}}\right)
$$

where the symbols $D_{o x}$ and $D_{c}$ now denote the diffusivity of the dissociation products through the oxide and coating, respectively.

Upon substituting Equation (26) from the Appendix, Equation (18a) becomes $A^{\prime}=A+2\left(\gamma_{o x} / \gamma_{c}\right) \delta$. Thus, the form of the equation for $A^{\prime}$ is the same whether the diffusants are the molecules $\mathrm{O}_{2}$ or $\mathrm{H}_{2} \mathrm{O}$ or the dissociation products $\mathrm{O}, \mathrm{O}^{2-}$, or $\mathrm{OH}^{-}$. It must be recognized, however, that $\gamma_{o x}$ and $\gamma_{c}$ now represent the permeability of the dissociation products.

Upon substituting Equation (17a), Equation (18b) becomes $B=2\left(D_{o x} / N_{1}\right) \sqrt{S_{o x} P}$, which is the expression one would obtain for $B$ with no coating, assuming there is dissociation and diffusion of the products through the oxide. Thus, whether the diffusants are molecular $\mathrm{O}_{2}$ or $\mathrm{H}_{2} \mathrm{O}$, or the products of their dissociation, $B$ is unaffected by the presence of a coating.

\subsection{Application}

Now the equations derived in the previous section are used to examine the results of oxidation experiments performed by Lee (2018) on environmental barrier coated CMC samples. The coating system is a two-layer system consisting of a layer of silicon bond coat with a nominal thickness of $125 \mu \mathrm{m}$ and a top layer of $\mathrm{Yb}_{2} \mathrm{Si}_{2} \mathrm{O}_{7}$ with a thickness of $254 \mu \mathrm{m}$. $\mathrm{Yb}_{2} \mathrm{Si}_{2} \mathrm{O}_{7}$ is a state-of-the-art coating used in EBCs for CMCs. The experiments were conducted at $1,316^{\circ} \mathrm{C}$ in two environments: (1) a wet oxygen environment of $90 \% \mathrm{H}_{2} \mathrm{O}$ and $10 \% \mathrm{O}_{2}$ at $1 \mathrm{~atm}$ total pressure and (2) air at $1 \mathrm{~atm}$. The silica TGO thickness was measured with a scanning electron microscope. The TGO thickness is plotted as a function of time in Figure 3 for the $90 \% \mathrm{H}_{2} \mathrm{O}+10 \% \mathrm{O}_{2}$ and air environments. Each data point represents an average of measurements at five or six locations.

A least-squares regression analysis was performed to obtain the best fit of Equation (14a) to the experimental data. The best-fit values for the constants $A^{\prime}, B$, and $\tau$ for the air environment are listed in Table I. A plot of Equation (15) using these values is shown in Figure 3. Also listed in Table I are the values for $A$ and $B$ for the oxidation of silicon in air without a coating. These were obtained by extrapolating the values for $A$ and $B$ listed in Deal and Grove (1965) for oxidation in dry oxygen to $1316^{\circ} \mathrm{C}$. Since $B$ is a linear function of the oxidant partial pressure (Deal and Grove, 1965), the extrapolated value for $B$ in dry oxygen was further modified to obtain its value in air: $B_{\text {air }}=0.21 B_{\mathrm{O}_{2}}$. A plot of the oxide growth on silicon in air without a coating using the extrapolated values for $A$ and $B$ in Table I is shown in Figure 3. 


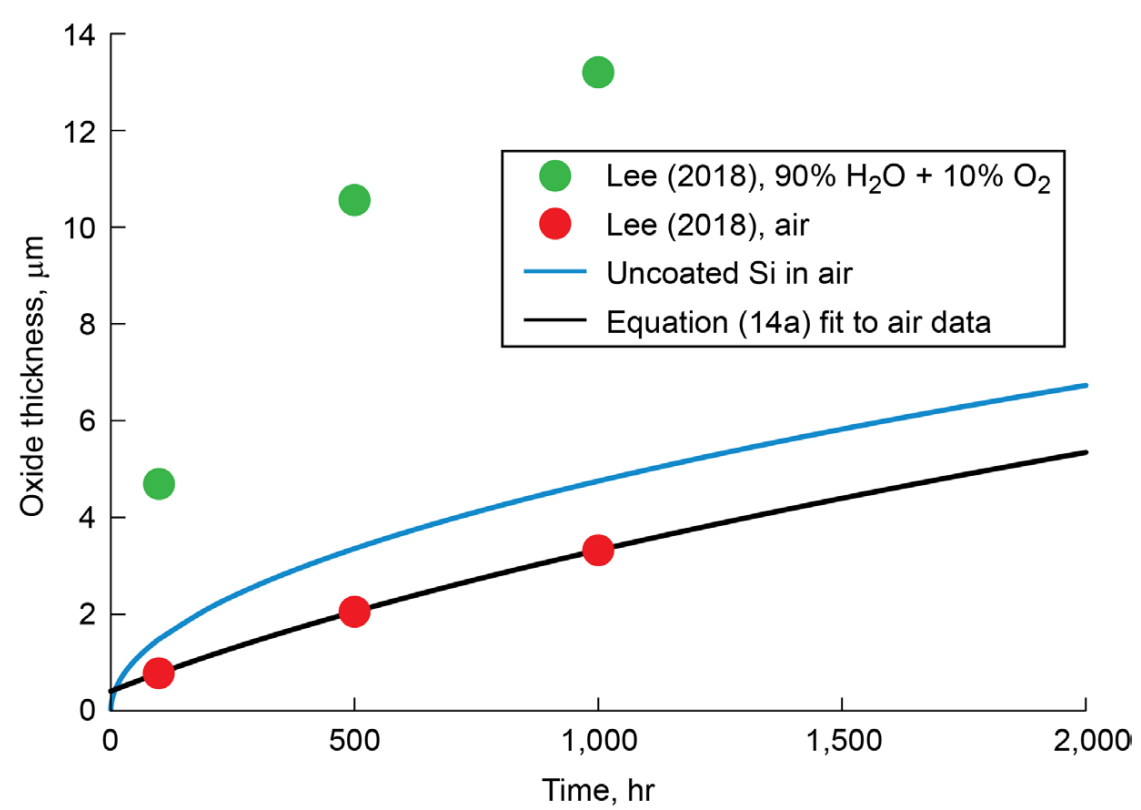

Figure 3.- Thermally grown oxide (TGO) thickness versus time for Si oxidation at $1,316^{\circ} \mathrm{C}$.

TABLE I.-LINEAR-PARABOLIC RATE CONSTANTS FOR OXIDATION OF Si WITH AND WITHOUT COATING [In air at $\left.1316^{\circ} \mathrm{C}.\right]$

\begin{tabular}{|c|c|c|c|c|c|}
\hline \multicolumn{3}{|c|}{ With coating $^{\mathrm{a}}$} & \multicolumn{3}{c|}{ Without coating $^{\mathrm{b}}$} \\
\hline $\begin{array}{c}A^{\prime}, \\
\mu \mathrm{m}\end{array}$ & $\begin{array}{c}B, \\
\mu \mathrm{m}^{2} / \mathrm{hr}\end{array}$ & $\begin{array}{c}\tau, \\
\mathrm{hr}\end{array}$ & $\begin{array}{c}A, \\
\mu \mathrm{m}\end{array}$ & $\begin{array}{c}B, \\
\mu \mathrm{m}^{2} / \mathrm{hr}\end{array}$ & $\begin{array}{c}\tau, \\
\mathrm{hr}\end{array}$ \\
\hline 7.4563 & 0.0326 & 98.49 & 0.03481 & $0.02275^{\mathrm{c}}$ & $0.01227^{\mathrm{d}}$ \\
\hline
\end{tabular}

${ }^{\mathrm{a}}$ Obtained by fitting equation (14a) to the results from Lee (2018).

${ }^{b}$ Extrapolated the constant values $A$ and $B$ from Deal and Grove (1965) for dry oxygen to $1316^{\circ} \mathrm{C}$.

${ }^{c}$ Modified further according to $B_{\text {air }}=0.21 B_{\mathrm{O}_{2}}$.

${ }^{\mathrm{d}}$ Assumes initial oxide thickness in dry oxygen at $1316^{\circ} \mathrm{C}$ is $0.023 \mu \mathrm{m}$ as in Deal and Grove (1965).

A similar approach was used to obtain the best-fit values of $A^{\prime}$ and $B$ for the $90 \% \mathrm{H}_{2} \mathrm{O}+10 \% \mathrm{O}_{2}$ environment, but the approach yielded negative values for $A^{\prime}$. Given Equations (7a) and (10), negative values of $A^{\prime}$ are not physically possible. The inability to obtain positive values for $A^{\prime}$ is most likely the result of having only three data points for fitting Equation (14a).

Note that the values for $B$ in Table I are different for the cases with and without a coating, but the previous derivations indicate that they should be the same. This discrepancy could also be the result of numerical error associated with having only three data points to fit to Equation (14a).

Using Equation (10), the values listed in Table I and $\delta=254 \mu \mathrm{m}$, one obtains

$$
\frac{\gamma_{o x}}{\gamma_{c}}=\frac{A^{\prime}-A}{2 \delta}=0.015
$$

for oxidation in air. This result suggests that at $1,316{ }^{\circ} \mathrm{C}$ the permeability of oxygen through $\mathrm{Yb}_{2} \mathrm{Si}_{2} \mathrm{O}_{7}$ is 67 times larger than the permeability of oxygen through silica in the testing conducted by Lee (2018). 
An estimate of the permeability of oxygen through silica at $1,316^{\circ} \mathrm{C}$ may be obtained by rewriting Equation (12) as

$$
\gamma_{o x}=H_{o x} D_{o x}=\frac{B N_{1}}{2 P}
$$

and by extrapolating the values for $B$ reported in Deal and Grove for dry oxygen to $1,316{ }^{\circ} \mathrm{C}$. The extrapolated value of $B$ at $1,316^{\circ} \mathrm{C}$ is $3 \times 10^{-13} \mathrm{~cm}^{2} / \mathrm{s}$. Recall from Deal and Grove that the values for $B$ in dry oxygen were obtained at $P=1 \mathrm{~atm}$ and that $N_{1}=2.25 \times 10^{22}$ molecule $/ \mathrm{cm}^{3}$ for oxidation in $\mathrm{O}_{2}$. This yields an estimated permeability of oxygen through silica of $\gamma_{o x}=5.6 \times 10^{-15} \mathrm{~mole} / \mathrm{atm} \cdot \mathrm{cm} \cdot \mathrm{s}$ at $1,316^{\circ} \mathrm{C}$. This value is consistent with the permeability values reported by Norton (1961). Norton measured the permeability of oxygen through silica at temperatures from 900 to $1,100{ }^{\circ} \mathrm{C}$. Extrapolating Norton's permeability values to $1,316^{\circ} \mathrm{C}$ yields a value of $\gamma_{o x}=3.2 \times 10^{-15} \mathrm{~mole} / \mathrm{atm} \cdot \mathrm{cm} \cdot \mathrm{s}$.

Using the permeability ratio from Equation (19) and the estimated permeability of oxygen through silica obtained by extrapolating the Deal and Grove data yields an estimated permeability of oxygen through the $\mathrm{Yb}_{2} \mathrm{Si}_{2} \mathrm{O}_{7}$ coating at $1,316^{\circ} \mathrm{C}$ of $\gamma_{c} \cong 3.73 \times 10^{-13} \mathrm{~mole} / \mathrm{atm} \cdot \mathrm{cm} \cdot \mathrm{s}$. In a similar manner, if Norton's data is used to estimate the oxide permeability, the coating permeability estimate is $\gamma_{c} \cong 2.13 \times 10^{-13} \mathrm{~mole} / \mathrm{atm} \cdot \mathrm{cm} \cdot \mathrm{s}$. These results are consistent with the results of oxygen permeability tests reported by Wada et al. (2017), where the oxygen permeation rate in $\mathrm{Yb}_{2} \mathrm{Si}_{2} \mathrm{O}_{7}$ wafer specimens was measured as a function of the $\mathrm{O}_{2}$ pressure differential at $1,400{ }^{\circ} \mathrm{C}$. The ratio of the permeation rate to the $\mathrm{O}_{2}$ pressure differential yields a permeability value of $\gamma_{c} \cong 2.3 \times 10^{-13} \mathrm{~mole} / \mathrm{atm} \cdot \mathrm{cm} \cdot \mathrm{s}$.

\subsection{Conclusions}

The results of this study reveal that the linear-parabolic growth equation of the form $x_{o}^{2}+A x_{o}=B(t+\tau)$ is applicable to the oxidation of the silicon bond coat in multilayer environmental barrier coating (EBC) systems. However, the constant $A$ must be modified according to $A^{\prime}=A+2 \gamma_{o x} \sum_{i=1}^{N} \delta_{i} / \gamma_{c i}$, where $\gamma_{c i}$ and $\delta_{i}$ represent the permeability and thickness of the coating layers, respectively. The constant $B$ is unaffected by the presence of a coating.

Application of the modified expression for $A$ to previous experimental results indicates that the permeability of oxygen through the $\mathrm{Yb}_{2} \mathrm{Si}_{2} \mathrm{O}_{7}$ coating is 67 times larger than the permeability of oxygen through silica at $1316{ }^{\circ} \mathrm{C}$. An estimate of the permeability ratio for the diffusion of water was not possible because of the limited number of data points previously reported for oxidation in the $90 \% \mathrm{H}_{2} \mathrm{O}+10 \% \mathrm{O}_{2}$ environment. When measuring the thermally grown oxide (TGO) thickness growth versus time it is desirable to have more than three data points to fit the data to Equation (14a). More research is needed to obtain the permeability of oxygen and water through the various EBC layers at the proposed service temperatures.

Equations (11) and (15) can be used to aid the design of EBC systems provided the coating layer permeability values are known. They may be utilized to select the minimum coating thickness necessary to maintain an acceptable silica layer thickness. Of course, this is only one tool for the design of EBC systems. These analyses must be performed in concert with thermal and structural analyses to ensure the structural integrity of the EBC over the service life of the coated component. 


\section{Appendix-Relationship Between Permeability and Diffusivity}

The relationship between permeability and diffusivity depends upon whether the diffusing oxidants are the molecules $\mathrm{O}_{2}$ or $\mathrm{H}_{2} \mathrm{O}$, or whether they are the products of the dissociation of $\mathrm{O}_{2}$ and $\mathrm{H}_{2} \mathrm{O}$, namely monatomic oxygen $\mathrm{O}$, or the ions $\mathrm{O}^{2-}$ or $\mathrm{OH}^{-}$. Consider the scenario illustrated in Figure 4, where a differential oxidant partial pressure $P^{A}-P^{B}$ is applied across a layer of solid with a thickness $L$. The solid may represent either oxide or coating. It is assumed that $P^{A}>P^{B}$, so the oxidant will flow from left to right. The permeability $\gamma$ is defined as the ratio of the oxidant mass flux $J$ (molecular, monatomic, or ionic) to the spatial gradient of the oxidant partial pressure. The concentrations $C^{A}$ and $C^{B}$ denote the boundary concentrations of $\mathrm{O}_{2}, \mathrm{H}_{2} \mathrm{O}, \mathrm{O}, \mathrm{O}^{2-}$ or $\mathrm{OH}^{-}$, depending upon the assumed nature of the diffusing oxidants. Steady-state conditions are assumed, so the concentration distribution is linear.

If the oxidant diffuses through the solid as either molecular $\mathrm{O}_{2}$ or $\mathrm{H}_{2} \mathrm{O}$, the concentration of the oxidant at the two boundaries is then given by Henry's law as $C^{A}=H P^{A}$ and $C^{B}=H P^{B}$, where $H$ is the Henry's law solubility coefficient. One could define the mass flux of oxidant from boundary A to boundary B using Fick's law:

$$
J=\frac{D}{L}\left(C^{A}-C^{B}\right)
$$

or one could define the oxidant mass flux in terms of the partial pressure differential using the definition of permeability:

$$
J=\frac{\gamma}{L}\left(P^{A}-P^{B}\right)
$$

For a molecular diffusant, $D$ and $\gamma$ in Equations (21) and (22) are, respectively, the diffusivity and permeability of the oxidant molecules $\left(\mathrm{O}_{2}\right.$ or $\left.\mathrm{H}_{2} \mathrm{O}\right)$ in the solid. Equating the mass flux expressions in Equations (21) and (22) and using the Henry's law expressions for the boundary concentrations yields

$$
\gamma=H D
$$

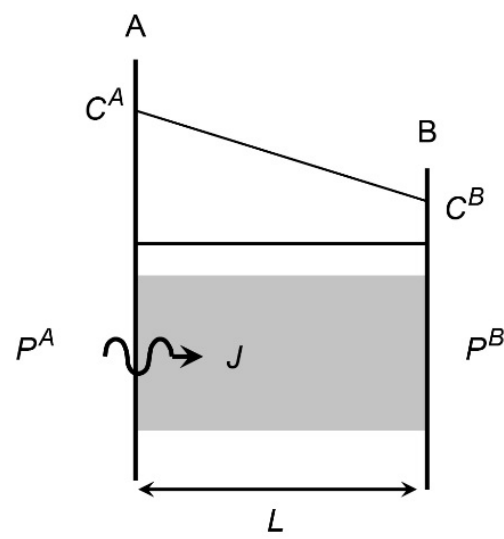

Figure 4.-Flux $J$ of oxidant through a solid of thickness $L$, driven by partial pressure differential $P^{A}-P^{B}$. $C^{A}$ and $C^{B}$ are concentration of oxidant at boundaries $A$ and $B$, respectively. 
It follows from Equation (23) that the ratio of the permeability of either $\mathrm{O}_{2}$ or $\mathrm{H}_{2} \mathrm{O}$ in the oxide to that in the coating may be written as

$$
\frac{\gamma_{o x}}{\gamma_{c}}=\frac{H_{o x} D_{o x}}{H_{c} D_{c}}
$$

where the subscripts $o x$ and $c$ refer to the oxide and coating, respectively.

If the diffusants are monatomic $\mathrm{O}$ or the ions $\mathrm{O}^{-}$or $\mathrm{OH}^{-}$, then the concentrations at the boundaries are given by Sieverts's law as $C^{A}=\sqrt{S P^{A}}$ and $C^{B}=\sqrt{S P^{B}}$, where $S$ is the Sieverts's law constant. In this case, the form of Equations (21) and (22) are still valid, but now $D$ and $\gamma$ are, respectively, the diffusivity and permeability of the dissociation products through the solid. Using Sieverts's law for the concentrations at the boundaries and equating the expressions in Equations (21) and (22) yields

$$
\gamma=\frac{D \sqrt{S}}{\left(\sqrt{P^{A}}+\sqrt{P^{B}}\right)}
$$

It follows from Equation (25) that for each dissociation product, the ratio of its permeability in the oxide to that in the coating may be written as

$$
\frac{\gamma_{o x}}{\gamma_{c}}=\frac{D_{o x} \sqrt{S_{o x}}}{D_{c} \sqrt{S_{c}}}
$$




\section{References}

Deal, B.E.; and Grove, A.S. (1965): General Relationship for the Thermal Oxidation of Silicon. J. Appl. Phys., vol. 36, no. 12, pp. 3770-3778.

Doremus, R.H. (1976): Oxidation of Silicon by Water and Oxygen and Diffusion in Fused Silica. J. Phys. Chem., vol. 80, no. 16, pp. 1773-1775.

Lamkin, M.A.; Riley, F.L.; and Fordham, R.J. (1992): Oxygen Mobility in Silicon Dioxide and Silicate Glasses: A Review. J. Eur. Ceram. Soc., vol. 10, no. 5, pp. 347-367.

Lee, Kang N. (2018): $\mathrm{Yb}_{2} \mathrm{Si}_{2} \mathrm{O}_{7}$ Environmental Barrier Coatings With Reduced Bond Coat Oxidation Rates via Chemical Modifications for Long Life. J. Am. Ceram. Soc., vol. 102, no. 3, pp. 1507-1521.

Norton, Francis J. (1961): Permeation of Gaseous Oxygen Through Vitreous Silica. Nature, vol. 171, p. 701. Richards, Bradley T., et al. (2016): Response of Ytterbium Disilicate-Silicon Environmental Barrier Coatings to Thermal Cycling in Water Vapor. Acta Mater., vol. 106, pp. 1-14.

Wada, Masashi, et al. (2017): Mass Transfer in Polycrystalline Ytterbium Disilicate Under Oxygen Potential Gradients at High Temperatures. Acta Mater., vol. 135, pp. 372-381.

Williams E.L. (1965): Diffusion of Oxygen in Fused Silica. J. Am. Ceram. Soc., vol. 48, no. 4, pp. 190-194. 


